\title{
Online Customer View: Positive Effect of Consumer Complaint in Domestic Appliance Purchase
}

\author{
Jiacan $\mathrm{Wu}^{\mathrm{a}}$, Ying $\mathrm{Tao}^{\mathrm{b}}$, Wei Zhang ${ }^{\mathrm{c}}$ and Mingfeng Wang ${ }^{\mathrm{d}}$ * \\ Technology center of China tobacco yunnan industrial Co., Ltd, Kunming 650231, China. \\ avolcano83@163.com, bcherry88@163.com, 'chwei7908@163.com, dhhwangmf@139.com
}

Keywords: Consumer complaint behavior, positive effect, online customer, purchase.

\begin{abstract}
Consumer complaint behavior (CCB) attracts increasing attention from most marketing scholars recently, but there are still few research focus on its positive effect from customer view. This study concentrates on online customer purchase behavior in domestic appliance, attempted to analyze the positive effect of CCB through observation, questionnaire survey and interview method. The study indicates that experienced online customers are inclined to cognize products which they are not familiar with by information collecting and processing from other customers' evaluation. Rather than positive customer evaluation, CCB could generate positive effect which can be more helpful for online customers' cognition, selection and purchase decision making on the products which they are not familiar with. The paper finds a new category of CCB, designs a new CCB taxonomy, proposes an Online Customer Product Evaluation Model (OCPE Model) based on domestic appliance purchase and provides some suggestion to companies on maximizing the positive influence caused by CCB.
\end{abstract}

\section{Introduction}

Nowadays, products updates rapidly with science and technology development in shorter time than ever. As one basic product category, domestic appliance is designed multifunctional, strong performanced and always with attractive appearance in an endless stream, which make customers unacquainted with them so that learn them by enough information just like learn some new products customers never know. As to online customer, they always finish product selection by $\mathrm{B} 2 \mathrm{C}$ or $\mathrm{C} 2 \mathrm{C}$ in the first time. So, learning by evaluations from other customers is a good way to getting information. When dissatisfaction occurs, consumer complaint behavior (CCB) emerges, and consumer complaint content $(\mathrm{CBC})$ is so useful for online customer to cognize product they want to purchase.

CCB has received increasing attention from researchers and practitioners alike (Ro \& Mattila, 2015; Kim, Lee \& Mattila, 2014; Kim \& Chen, 2010; Kucuk 2008; Hong \& Lee, 2005; Jones, McCleary \& Lepisto, 2002; Kolodinsky 1995; Singh 1988; Day 1977, 1984; TARP 1980, 1985) ${ }^{[1-12]}$ in the last 38 years. It is believed that $\mathrm{CCB}$, especially consumer private complaint behavior (CPCB), as one basic form of $\mathrm{CCB}$, according to $\mathrm{CCB}$ classifications proposed by researchers (Davidow \& Dacin 1997; Singh 1988; Day \& London 1977) ${ }^{[13-15]}$, is the most harmful behavior to companies by its privacy and uncontrollability. For online customers, according to our survey results, it's so interesting that they wish to see both positive and negative evaluations about products from other customers, especially CBC.

Hence, the objectives of this study are:

1. To confirm CCB categories refer to online customer purchase;

2. To analyze the positive effect of CCB for online customer;

3. To construct the model of online customer product evaluation.

\section{Review of Literature}

Concept of Consumer Complaint Behavior (CCB). Researches on CCB began from 70s in last century. Several definitions have been proposed. Jacoby and Jaccard (1981) suggested that consumer complaint behavior is generally related to the emotional reactions of dissatisfied consumers due to a product and/or service failure ${ }^{[16]}$. Singh (1988) supposed that CCB is conceptualized as a set of 
multiple (behavioral and nonbehavioral) responses, some or all of which are triggered by perceived dissatisfaction with a purchase episode ${ }^{[17]}$.

There is considerable agreement about the conceptual meaning of consumer complaint behavior that it is believed that the CCB phenomenon is drived by some feelings or emotions of perceived dissatisfaction (Day 1984; Landon 1980) ${ }^{[18,19]}$.

Classification of Consumer Complaint Behavior (CCB). We could realize by the CCB concepts that $\mathrm{CCB}$ responses generally are considered to fit into two broad categories, behavioral and nonbehavioral. Behavioral responses focus on the consumer's actions that convey an "expression of dissatisfaction" (Landon, 1980) ${ }^{[20]}$. And of course, consumer's behavioral responses could not be towards to the sellers directly, but also to the manufacturers and retailers, etc. While some consumers take behavior responses, the others take nonbehavioral ones, Day et al. $(1981)^{[21]}$. For example, the consumer forgets about a dissatisfying episode and does nothing, should be considered as legitimate CCB responses. Sometimes, consumer will not do behavioral responses because of timing, financial cost or physical cost, but which doesn't mean consumer is satisfied.

With a review of CCB literature, we find Day $(1977,1980)^{[22,23]}$ and Singh $(1988)^{[24]}$ proposed their representative CCB taxonomies. The first CCB taxonomy is advised by Day and Landon (1977) ${ }^{[25]}$. They suggest that CCB should be classified in a two-level hierarchically. In the first level, CCB could be distinguished behavioral response from nonbehavioral response. In the second level, behavioral response could be classified with public action and private action. The public response including seeking redress, legal action and complaining to public. The private response including two typical action, boycotting and word-of-mouth communication with friends. We can see it clearly by their classification schema (see Fig. 1).

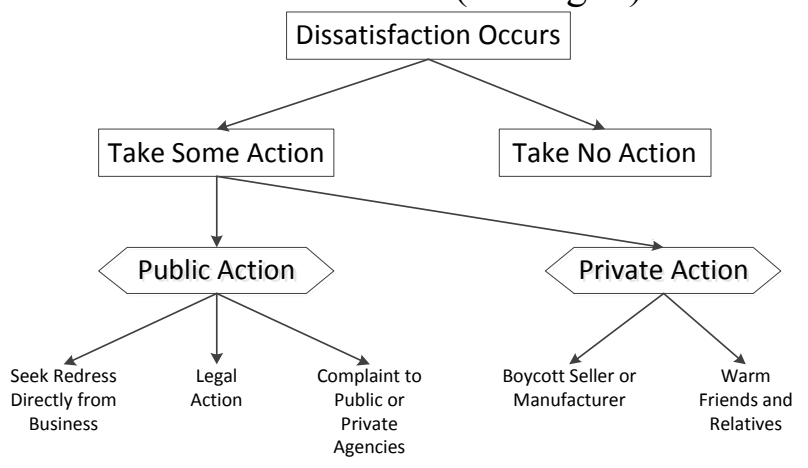

Fig. 1 Day and Landon's classification

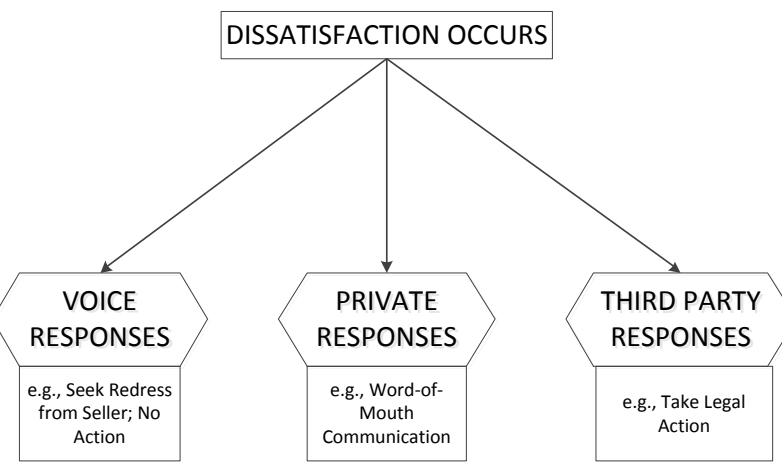

Fig. 2 Singh's Taxonomy

Day (1980) modifies the classification at the second level ${ }^{[26]}$. He noted consumers complain to achieve specific objectives with their various "explanations" for complaint action they take. Day proposed that the complaint motive can be used to classify behavioral CCB into three broad categories: redress seeking, complaining and personal boycott.

Singh (1988) conducts his study with 4000 questionnaires sending out and posed his taxonomy of CCB responses (see Fig. 2) ${ }^{[27]}$. By confirmatory analysis, he argues that CCB responses could be classified into three categories.

1. Voice responses. It is a direct complaint behavior including seeking redress from seller and no action, etc.

2. Private responses. It is a indirect complaint behavior including word- of- mouth communication, etc.

3. The third party responses. It means taking legal action, etc.

We consider that Singh's CCB taxonomy is more clear for his classification is in one- level hierarchy. We believe that, the action appearance but not consumer's motive is more scientific, because consumer's motive is far beyond the three ones suggested by Day (1980) but always in the three type advised by Singh (1988). So, We choose Singh's CCB taxonomy as theoretical basis.

Word-of-Mouth (WOM). Word-of-mouth (WOM) behavior has received few attention from researchers. From a marketing perspective, Dichter (1966) proves that WOM communication is a major type of advertising and advanced the principle of WOM advertisement ${ }^{[28]}$. Arndt (1968) 
describes WOM communication as simply "oral, person-to-person communication between a perceived non-commercial communicator and a receiver regarding a brand, a product, or a service " [29]. Westbrook (1987) considers WOM communication "consist of informal communications directed at other consumers about the ownership, usage, or characteristics of particular goods and services and/or their sellers" ${ }^{[30]}$. Some scholars believe that only positive and not negative WOM is used to inform others about new products rather than existing products and it has limited influence. On the other hand, some scholars hold opposite view. Richins (1983) proves that the negative WOM is one basic type of CCB responses and it has a great influence on the other consumers ${ }^{[31]}$. Stephens and Gwinner (1998) proposes that WOM communication has a strong ripple effect which could help companies create more loyal customer ${ }^{[32]}$.

Hence, we could think that WOM could have a big and far power of influence but not a limited one on other related people directly or indirectly.

\section{Methodology}

Sample Design. Ideal sample, first of all, should be online customer with not less than 2 years' experience of online shopping because inexperienced online customer is always lack of shopping skills and 2 years could be acceptable according to Constantinides's research (1990) ${ }^{[33]}$. And also, the sample should have domestic appliance online purchase experience or plan so they could think it over that how to purchase satisfying products online. What's more, college trained customer would be preferred, which means they are the adults who could perceive products sanely.

Questionnaire Discrimination. Respondents were asked to record information regarding their direct experience of online shopping on a standardized form both online and intercept visit on the road. A valid sample of 203 adults between the ages of 22 to 44 is available. All of the respondents are Chinese. The respondents were enrolled in 19 different provinces. Demographic characteristics of the sample are provided in Table 1. As seen in Table 1, a strength of the sample utilized for this study is the diversity of the respondents.

Table 1 Respondent characteristics

\begin{tabular}{cccc}
\hline Numble of provinces & Gender & Age (years) & Experience (years) \\
\hline \multirow{2}{*}{19} & 80 males & $20-29(75$ respondents $)$ & $2-5$ (78 respondents) \\
& 123 females & $30-39(105$ respondents $)$ & $5-10(116$ respondents $)$ \\
& & $40-49(23$ respondents $)$ & 10 above $(9$ respondents $)$ \\
\hline
\end{tabular}

Interview Method. Respondents were interviewed in 20 groups by researchers and interview outline was designed in terms of the motivation, process and method of their domestic appliance online purchase behavior. For the 19 cooperative respondents with rigorous verbal expression the study selected, they were invited to participate in deep interview individually. Deep interview was not structurized and the topic is still domestic appliance online purchase behavior. Compared to group interview, deep interview focus on the behavioral details much more.

\section{Analysis and Results}

New Taxonomy of CCB. Almost all of the respondents would attempt to acquaint themselves with customer evaluation both online and offline but not just online customer evaluation only when they prepared to make online purchase on domestic appliance. It is a remarkable fact that there are 2 types of customer evaluation by content which are product evaluation and service evaluation. Product evaluation is just about the quality of the product itself and service evaluation is referred to all the other things supplied by seller except the product including delivery service which is so important in online shopping. Accordingly, as one kind of negative evaluation, CCB could have 2 types by content. Considering propagation medium, the paper provides a new taxonomy of CCB in figure 3. 


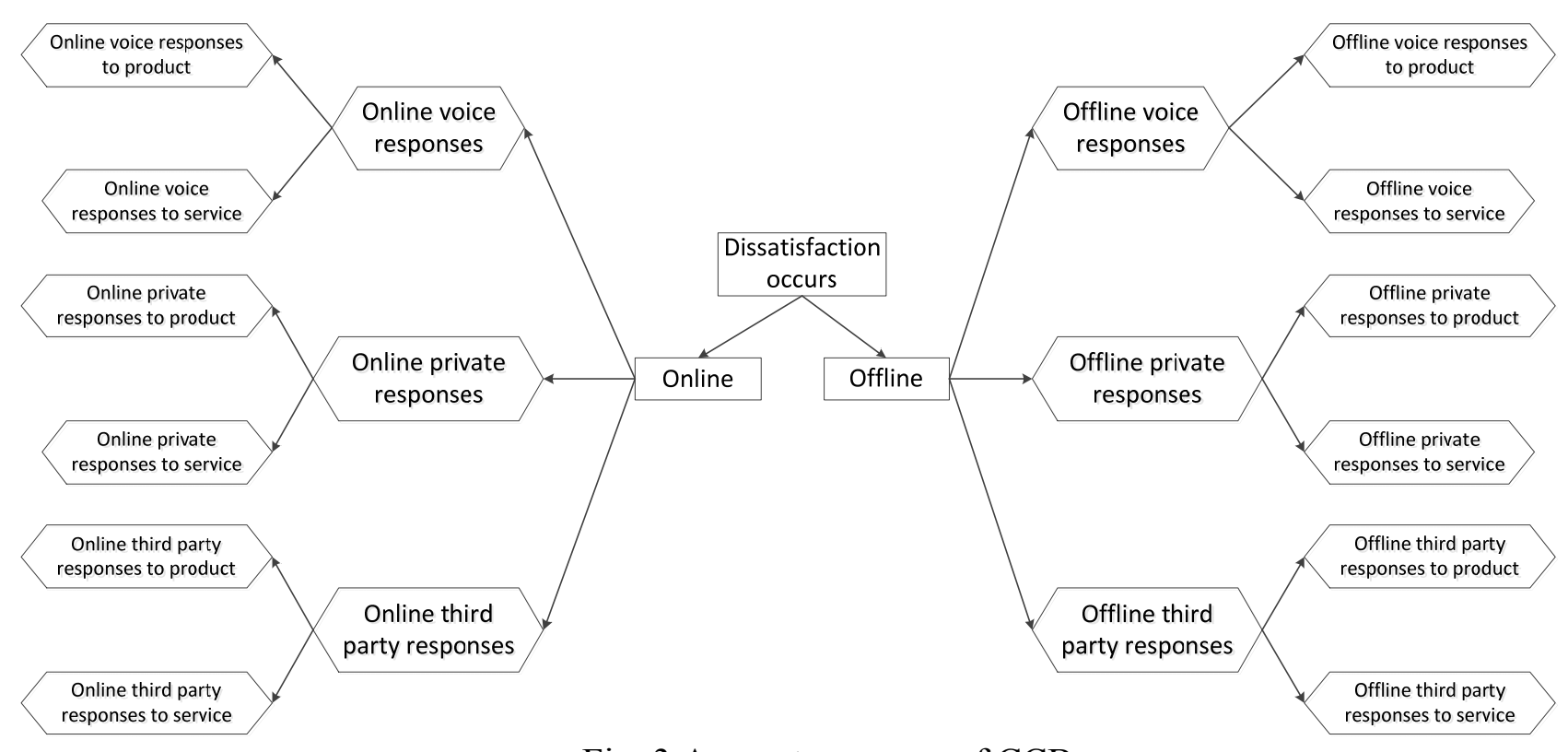

Fig. 3 A new taxonomy of CCB

Online Customer Product Evaluation Model. This study found that almost all of the respondents believed that $\mathrm{CCB}$ or other negative evaluation is more useful than positive evaluation that's because they could realize product more objectively by CCB which is always in details but not positive evaluation which is always general. What's more, they did not mind CCB to service especially online service attitude except that they need the product as soon as possible. And, generally speaking, the positive evaluation about product is more concerned by them. So, if online evaluation about product coincided with offline evaluation about product, it's so easy for the respondents to make decision to accept or not. Specifically, if both online ones and offline ones were positive, the respondents are inclined to purchase; if negative, they switch to other products probably. In 2 circumstances above, CCB's positive effect does not exist. Only when online ones disagree with offline ones, the positive effect of $\mathrm{CCB}$ could be found. The condition of CCB's positive effect is provided in Table 2 .

Table 2 Condition of CCB's positive effect

\begin{tabular}{ccc}
\hline Type of evaluation & P online & N online \\
\hline P offline & $\sqrt{ }$ & $\times$ \\
N offline & $\times$ & $\sqrt{ }$ \\
\hline
\end{tabular}

$\mathrm{P}$ : positive evaluation; $\mathrm{N}$ : negative evaluation

Under this condition, customer could gather product evaluations both positive and negative online or offline. The respondents with more years of online shopping experience would make a study on product by analysis of the CCB to product no matter online or offline in some method like Grounded Research. They would mine some product features by coding the content of CCB, and then, pick some ones they emphasized out and confirm. After that, they would analyze the parts referred to the features they emphasized carefully and seek more credible description from close friends but not online customers. Then, they contrast their conclusion with others' description and make decision at last. If their conclusions agree with the description, they make decision easily. Otherwise, they would like to make purchase decision based on the description from close friends much more than their conclusion of their analysis (see Fig. 3). 


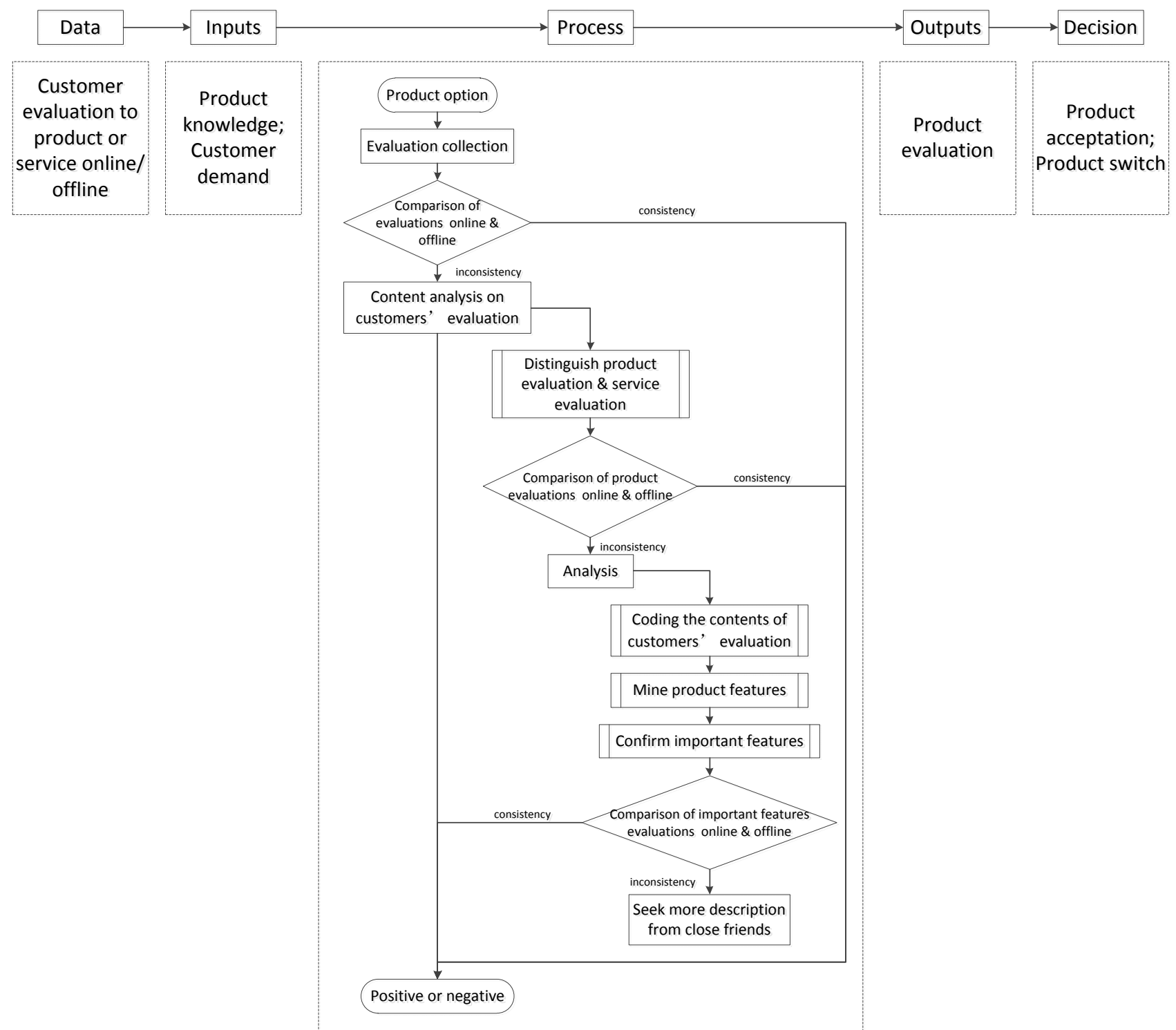

Fig. 3 Online customer product evaluation model

\section{Conclusion and Implication}

The study found the positive effect of CCB for online customer purchase. Based on above, we could learn that the positive effect is conditional and it's powerful in online shopping. For online customer, making a good use of CCB from other customers is always meant to make a good purchase decision. On the other hand, it's obvious that companies should focus on online CCB to their products.

\section{Acknowledgments}

This work was financially supported by "Research on Product Development Technology of Yunnan-make Cigarette Adapt to Tobacco Control Environment" (2015CP08), Science and Technology Project of China tobacco yunnan industrial Co., Ltd.

\section{References}

[1] H. Ro, A.S. Mattila, R.A. Lupton, Silent voices: Nonbehavioral reactions to service failures, J. Services Marketing Quarterly, 2015, 36(2): 95-111. 
[2] M.G. Kim, C.H. Lee, A.S. Mattila, Determinants of customer complaint behavior in a restaurant context: The role of culture, price level, and customer loyalty, J. Journal of Hospitality Marketing \& Management, 2014, 23(8): 885-906.

[3] J.H. Kim, J.S. Chen, The effects of situational and personal characteristics on consumer complaint behavior in restaurant services, J. Journal of Travel \& Tourism Marketing, 2010, 27(1): 96-112.

[4] S.U. Kucuk, Consumer exit, voice, and 'power'on the internet, J. Journal of Research for Consumers, 2008, 15(1): 1-13.

[5] J.Y. Hong, W.N. Lee, Consumer complaint behavior in the online environment, J. Web Systems Design and Online Consumer Behavior, 2005, 90-105.

[6] D.L. Jones, K.W. McCleary, L.R. Lepisto, Consumer complaint behavior manifestations for table service restaurants: Identifying sociodemographic characteristics, personality, and behavioral factors, J. Journal of Hospitality \& Tourism Research, 2002, 26(2): 105-123.

[7] J. Kolodinsky, Usefulness of economics in explaining consumer complaints, J. Journal of Consumer Affairs, 1995, 29(1): 29-54.

$[8][14][17][24][27] J$. Singh, Consumer complaint intentions and behavior: definitional and taxonomical issues, J. The Journal of Marketing, 1988: 93-107.

[9][22][25]R.L. Day, E.L. Landon, Toward a theory of consumer complaining behavior, J. Consumer and industrial buying behavior, 1977, 95: 425-437.

[10][18]R.L. Day, Modeling choices among alternative responses to dissatisfaction, J. Advances in consumer research, 1984, 11(1): 496-499.

[11] Technical Assistance Research Programs (Firm), Consumer Complaint Handling in America: Final Report, TARP, 1980.

[12] Technical Assistance Research Programs (Firm), Consumer Complaint Handling in America: An Update Study, TARP, 1985.

[13]M. Davidow, P.A. Dacin, Understanding and influencing consumer complaint behavior: improving organizational complaint management, J. Advances in Consumer Research, 1997, 24(1): 450-456.

[15]R.L. Day, M. Bodur, A comprehensive study of satisfaction with consumer services, J. Consumer Satisfaction Dissatisfaction and Complaining Behavior, Indiana University, 1977.

[16] J. Jacoby, J.J. Jaccard, The sources, meaning, and validity of consumer complaint behavior: A psychological analysis, J. Journal of retailing, 1981, 57 (3): 4-24.

[19][20]E.L. Landon Jr., The direction of consumer complaint research, in: J.C. Olson (Eds.), Advances in Consumer Research, Association for Consumer Research, Michigan, 1980, pp. 335-8.

[21] R.L. Day, K. Grabicke, T. Schaetzle, et al., The hidden agenda of consumer complaining, J. Journal of Retailing, 1981, 57 (3): 86-106.

[23][26] R.L. Day, Research perspectives on consumer complaining behavior, in: L. Charles, D. Patrick (Eds.), Theoretical Developments in Marketing, American Marketing Association, Chicago, 1980, pp. 211-15.

[28]E. Dichter, How word-of-mouth advertising works, J. Harvard business review, 1966, 44(6): 147-160.

[29] J. Arndt, Role of product-related conversations in the diffusion of a new product, J. Journal of Marketing Research, 1967, 4(1): 291-295. 
[30]R.A. Westbrook, A rating scale for measuring product/service satisfaction, J. The Journal of Marketing, 1980, 3: 68-72.

[31] M.L. Richins, Negative word-of-mouth by dissatisfied consumers: A pilot study, J. The Journal of Marketing, 1983, 3: 68-78.

[32] N. Stephens, K.P. Gwinner, Why don't some people complain? A cognitive-emotive process model of consumer complaint behavior, J. Journal of the Academy of Marketing Science, 1998, 26(3): 172-189.

[33] G.M. Constantinides, Habit formation: A resolution of the equity premium puzzle, J. Journal of Political Economy, $1990: 519-543$. 